\title{
Tracheal Agenesis: A Case Report Emphasizing the Use of a Laryngeal Mask Airway
}

Richelle M. Reinhart, MD, Morarii R. Peesay, MD, Nitin R. Mehta, MD

"Here we present a case where a preterm infant with severe Tracheal Agenesis (TA) was successfully intubated with LMA during resuscitation at birth and ultimately transferred to a Level IV NICU for a tracheostomy."

\section{Introduction:}

A significant amount has been learned in the past few decades about the basics of using Laryngeal Mask Airway (LMA) intuba- tion, but much remains to be determined about its practical use. Recently, renewed interest in its usage was supported by the Neonatal Resuscitation Program (NRP) course, and, thus, there is increased awareness of managing an airway via LMA. Here we present a case where a preterm infant with severe Tracheal Agenesis (TA) was successfully intubated with LMA during resuscitation at birth and ultimately transferred to a Level IV NICU for a tracheostomy. TA is rare and usually fatal. Few survivors with concomitant Tracheoesophageal Fistula (TEF) who underwent ligation of the distal esophagus with the creation of a spit-fistula and neo-trachea from the proximal esophagus exist. To our knowledge, this case of Tracheal Agenesis is the first of its kind to be reported as successfully managed via LMA.

\section{Case description:}

A preterm infant of 34-weeks gestational age was delivered to a 36-year-old Black mother. This was an in vitro fertilization pregnancy with appropriate prenatal care, complicated only by polyhydramnios. She had been found to have a 2-vessel umbilical cord with a subsequent normal fetal echocardiogram. The mother was admitted in spontaneous labor without evidence of chorioamnio-

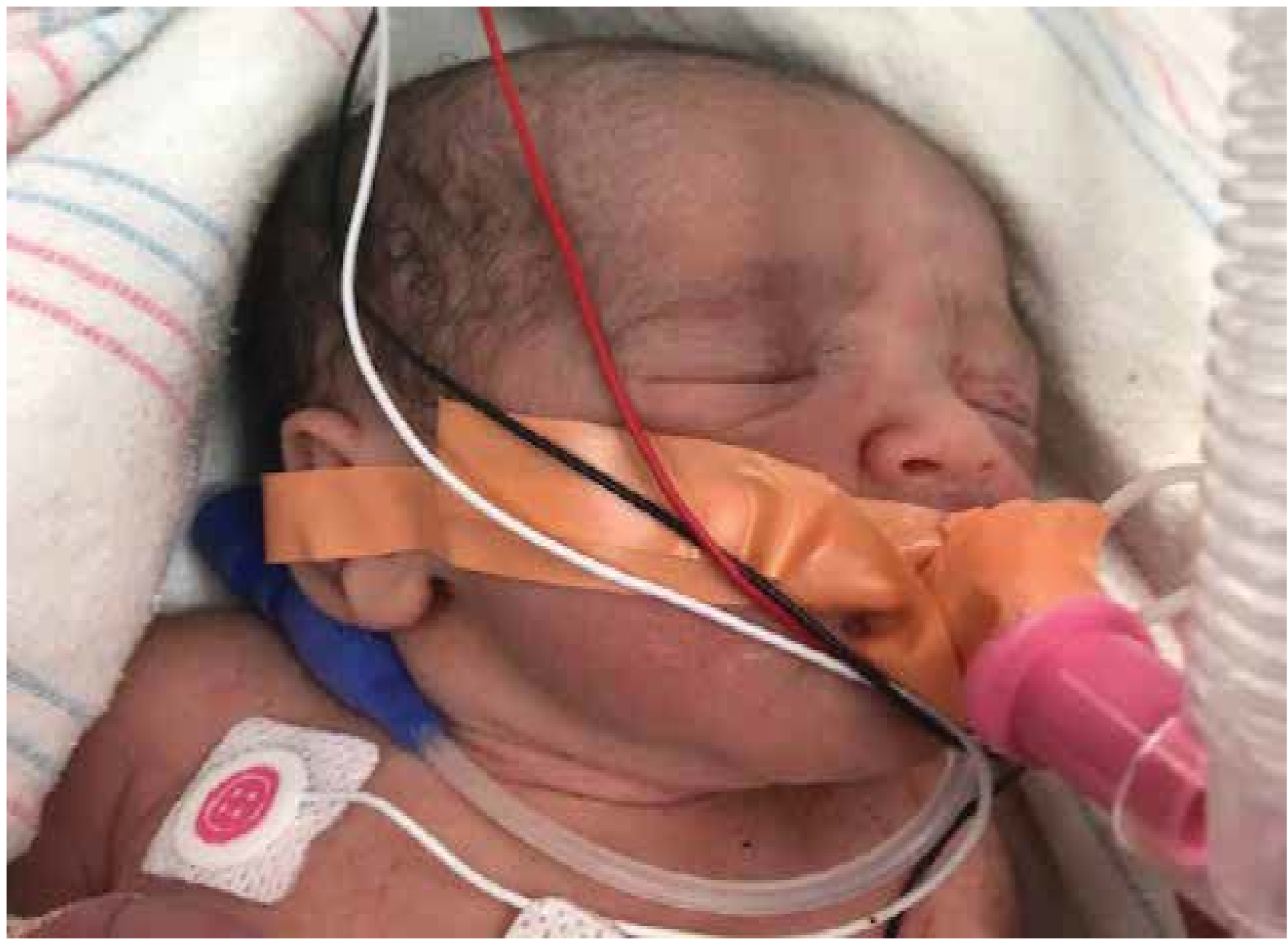

Figure 1. Infant described in the case report with LMA securely in place for transport. 

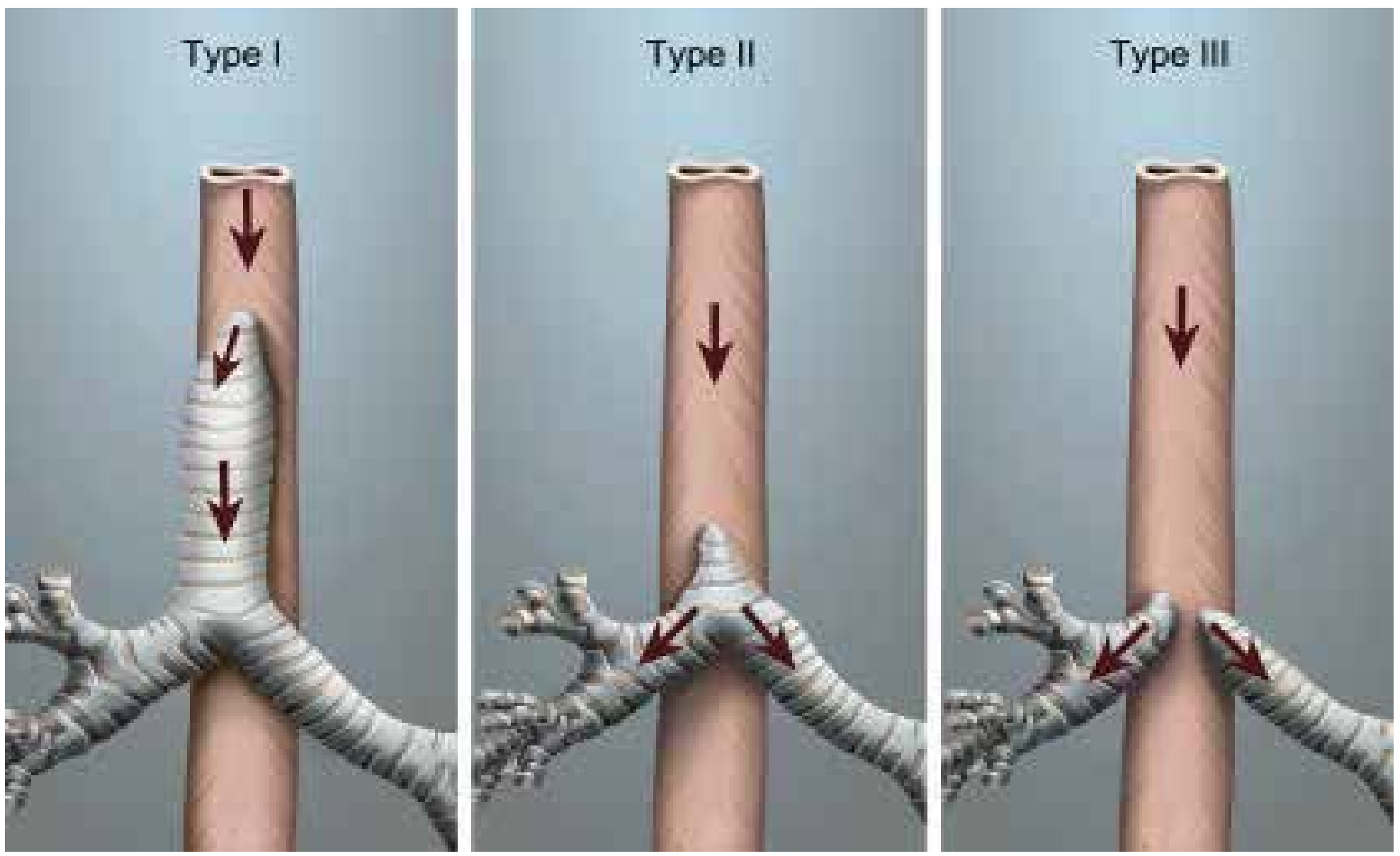

Figure 2. Floyd's classification of tracheal agenesis.(6)

nitis and received one dose of betamethasone prior to delivery. Prenatal labs negative for HBsAg, HIV, RPR, GC, Chlamydia; GBS was unknown. The infant was delivered by cesarean section for breech positioning with difficult extraction secondary to footling presentation. At birth, the infant was apneic and hypotensive with a low heart rate. Despite visualization of cords, intubation was unsuccessful with an inability to advance the tube with 3.0, 2.5, and 2.0 endotracheal tubes. Ultimately, a premature infant size LMA was placed and secured with subsequent improvement in her heart rate, oxygen saturation, and color. The LMA was secured, and she stabilized on the ventilator. On exam, she had no significant anomalies other than the previously known 2-vessel cord. Her birth weight was 2200 grams, and APGAR scores were as follows: 1, 4, 2, 7, and 8 at 1, 5, 10, 15, and 20 minutes, respectively. The infant was then transferred to a tertiary care center on LMA ventilation (Figure 1). On arrival to the NICU, she was taken to emergent explorative surgery and found to have tracheal agenesis, Floyd Type 1. She required extracorporeal membranous oxygenation (ECMO) but was ultimately provided with a neo-trachea via a novel approach by ENT and pediatric surgery. (1) She was discharged home after ten months in the NICU, status-post trachealization of her esophagus with a tracheostomy and gastric tube in place. She initially did well after discharge with normal neurological development until she passed away from accidental

decannulation at 16 months.

\section{Discussion:}

It is unclear how aerodynamics worked out in this case of Tracheal Agenesis with TEF. Based on exploration by ENT, the patient's cervical trachea was missing. There seemed to be TEF (Floyd Type I) with the remaining short distal trachea that could potentially be ventilated via the fistula. The three Floyd classifications of TA are as follows: I $(20 \%)$ - atresia of the proximal trachea with a short distal trachea, normal bronchi, and a TEF; II (60\%) - complete tracheal atresia with normal carina and bifurcation of the bronchi; III $(20 \%)$ - complete tracheal atresia with bronchi arising directly from the esophagus (Figure 2). (2) In such situations where TEF is suspected, LMA intubation (or accidental esophageal intubation) may improve the respiratory status temporarily. TA should be at the top of a differential for any patient who is either having difficulty being intubated or experiencing severe cyanosis with respiratory distress immediately after birth without an audible cry. As with our patient, about half of patients with TA have abnormal prenatal ultrasounds, with polyhydramnios reported most commonly. (3) Many are born prematurely, and most patients have another associated anomaly. (4) There is a known high mortality rate in infants with this rare malformation, with only a 3-month-survival of less than $10 \%$. (3) Tracheotomy is often attempted after birth once

NEONATOLOGY TODAY is interested in publishing manuscripts from Neonatologists, Fellows, NNPs and those involved in caring for neonates on case studies, research results, hospital news, meeting announcements, and other pertinent topics.

Please submit your manuscript to: LomaLindaPublishingCompany@gmail.com 
the diagnosis is suspected; however, for many newborns, survival until surgery is not possible. Airway management is the most critical part of care in any infants who survive. In one large systematic review of patients with TA, airway management occurred most often via esophageal intubation (38\%), with some version of surgical airway placement (cervical exploration, gastrostomy, cervical esophagostomy, etc.) occurring with the majority of the remaining patients. (5)

\section{"This report encourages the use of LMA not only in situations where there is a concern for airway obstruction but also whenever there is difficult intubation, or alternative modes of management are needed, per NRP."}

\section{Conclusion:}

This report describes a successful airway management case in Tracheal Agenesis with LMA intubation and transport on LMA ventilation. This report encourages the use of LMA not only in situations where there is a concern for airway obstruction but also whenever there is difficult intubation, or alternative modes of management are needed, per NRP. Proactive thinking of the use of LMA is emphasized in place of Bag and Mask Ventilation as primary resuscitation equipment in difficult-to-manage airways.

\section{References:}

1. Straughan AJ, Mulcahy CF, Sandler AD, Bauman NM, Steinhorn D, Gitman L. Tracheal Agenesis: Vertical Division of the Native Esophagus - A Novel Surgical Approach and Review of the Literature. Ann Otol Rhinol Laryngol. 2020 Oct 8:3489420962124. doi: 10.1177/0003489420962124. Epub ahead of print. PMID: 33030043.

2. Seidman AP, Sinz EH, Goldenberg D. Tracheotomy Management: A Multidisciplinary Approach. Cambridge University Press. 2011 October 20;66-67.

3. Ergun S, Tewfik T, Daniel S. Tracheal agenesis: A rare but fatal congenital anomaly. Mcgill J Med. 2011;13(1):10.

4. Smith MM, Huang A, Labbé M, Lubov J, Nguyen LHP. Clinical presentation and airway management of tracheal atresia: A systematic review. Int J Pediatr Otorhinolaryngol. 2017 Oct; 101:57-64.

5. de Groot-van der Mooren MD, Haak MC, Lakeman P, et al. Tracheal agenesis: approach towards this severe diagnosis. Case report and review of the literature. Eur J Pediatr. 2012;171(3):425-431.

6. Congenital Tracheal Anomalies. Ento Key: Fastest Otolaryngology and Ophthalmology Insight Engine. Updated April 2, 2017. Accessed April 16, 2021. https://entokey.com/congenital-tracheal-anomalies/\#fig1.

Disclosures: The authors have no disclosures or conflicts of interest relevant to this case report.
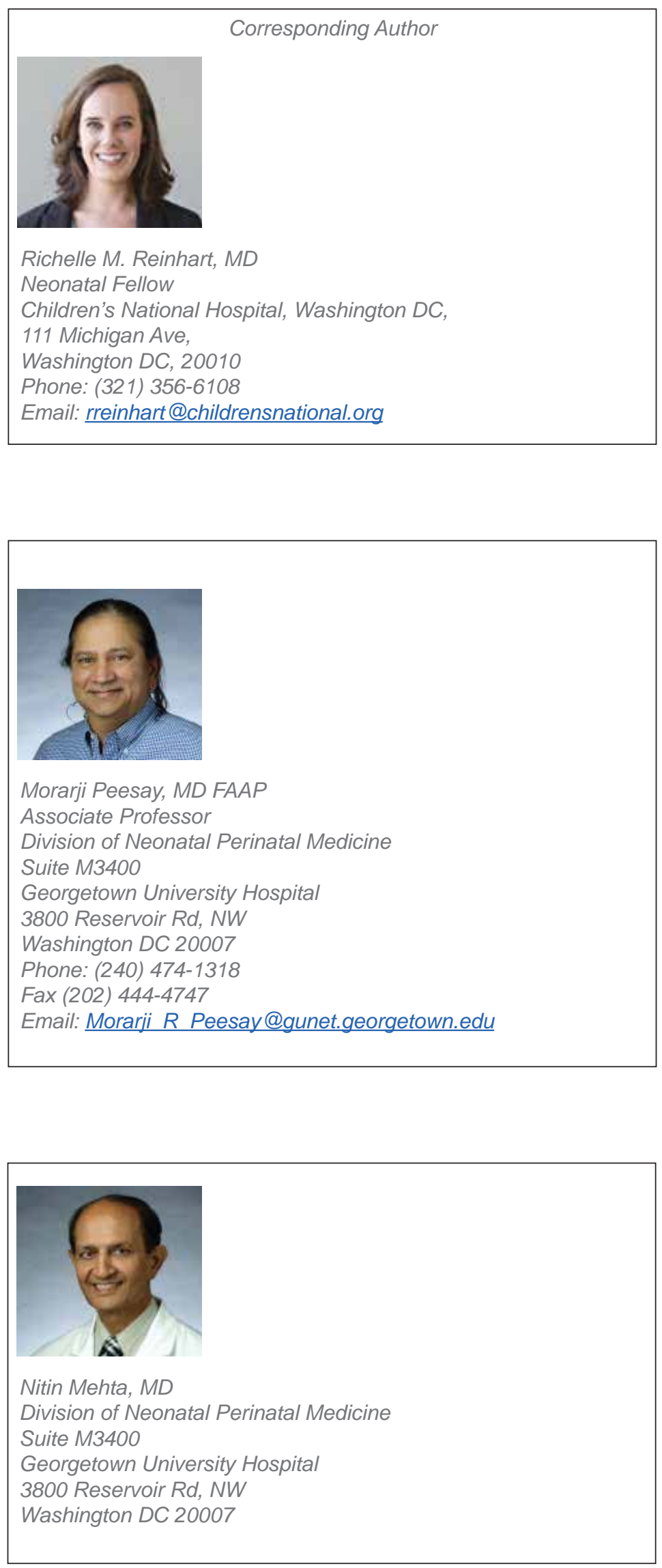